\title{
Release of B cell-activating factor of the TNF family in bronchoalveolar lavage from Behçet disease with pulmonary involvement
}

\author{
Agnès Hamzaoui, ${ }^{1,2, *}$ Hanene Chelbi, ${ }^{2}$ Fayçal Hai Sassi ${ }^{2}$ and Kamel Hamzaoui ${ }^{2}$ \\ 'Abderrahmen Mami Hospital; Ariana, Tunisia; ${ }^{2}$ Medicine Faculty of Tunis; University El Manar; Tunis, Tunisia
}

Key words: B cell-activating factor of the TNF family, Behçet disease, IL-6, IL-13, bronchoalveolar lavage

\begin{abstract}
Pulmonary artery aneurysms, arterial and venous thrombosis, pulmonary infarction, recurrent pneumonia, bronchiolitis obliterans organized pneumonia, and pleurisy are the main features of pulmonary involvement in Behçet disease. The objective of this study was to investigate the production of B-cell-activating factor of the TNF family (BAFF), an important regulator of B-cell survival and immunoglobulin class-switch recombination, in bronchoalveolar lavage (BAL) fluid from $B D$ patients having pulmonary manifestation. Bronchoalveolar lavage (BAL) was performed in $15 \mathrm{BD}$ patients with pulmonary manifestation and $18 \mathrm{BAL}$ from healthy controls. Concentrations of B-cell-active cytokines, including BAFF, IL-6 and IL-13, were measured by using specific ELISA and cytometric bead array assays. Levels of BAFF protein were significantly increased in BAL fluid from active BD $(109 \pm 21.78 \mathrm{pg} / \mathrm{mL})$ compared with those oh healthy controls (4.83 \pm $1.75 \mathrm{pg} / \mathrm{mL} ; \mathrm{p}<0.0001)$. In the BAL fluid, BAFF levels were significantly correlated with absolute numbers of total cells $(r=$ $0.823 ; p<0.0001)$, lymphocytes $(r=0.709 ; p<0.0001)$, neutrophils $(r=0.809 ; p<0.0001)$ and macrophages $(r=0.742 ; p<$ $0.0001)$. Normalization to albumin indicated that BAFF production occurred locally in the airways. BAFF levels were also significantly correlated with the other B-cell-activating cytokines IL-6 $(r=0.882, \mathrm{p}<0.001)$ and IL-13 $(r=0.659, \mathrm{p}<0.001)$. The antigen-induced production of BAFF in the lung of active BD with pulmonary manifestations might contribute to immunoglobulin synthesis by B-cells. The cells residing in the lung might affect each other through BAFF.
\end{abstract}

\section{Introduction}

Behçet disease (BD) is a multi-system inflammatory disorder, currently classified as a vasculitis. Its etiopathogenesis is unclear, but environmental, genetic and autoimmune factors have been considered. There have been ongoing efforts to elucidate the aetiology of BD. Many studies have investigated genetic aspects and immunologic features of the disorder. However, there is certainly a need for more prospective, controlled and longitudinal studies — not an easy endeavour considering the heterogeneity of BD. Immunological studies were needed particularly in inflammatory sites as the lung. The International Study Group for Behçet Disease has established diagnostic criteria for $\mathrm{BD}$, which make recurrent oral ulcers a mandatory finding, along with two of the four: recurrent genital ulcers, eye involvement, skin lesions and pathergy. While various tissue types such as blood vessel, eye, skin, mucosa, joint or central nervous system (CNS), may be affected during the course of $\mathrm{BD}$, lung involvement, remains one of the most serious complications of the disease. ${ }^{2}$ Large vessel vasculitis in BD may affect the pulmonary arteries, the aorta and other major peripheral vessels. ${ }^{3-6}$
BAFF has been recognized to mainly be a product of myeloid cells, such as monocytes, macrophages, dendritic cells (DCs) and neutrophils. ${ }^{7,8}$ In airway inflammatory diseases local B-cell class-switch recombination can mediate activation of airways in response to antigen exposure. ${ }^{9,10} \mathrm{~B}$-cellactivating factor of the TNF family (BAFF, also known as BLyS, TNFSF13B, TALL-1 and THANK) is a member of the TNF superfamily that plays important roles in B-cell survival, proliferation and maturation. ${ }^{11}$ BAFF binds to 2 high-affinity receptors that are selectively expressed on B-cells, including BAFF receptor and transmembrane activator and CAML interactor (TACI). BAFF can also bind to a low-affinity receptor, B-cell maturation antigen. ${ }^{12}$ Recently, it has been reported that BAFF is produced by bronchial epithelial cells and nasal epithelial cells. ${ }^{13}$

In the present study we investigated BAFF expression in the bronchoalveolar lavage (BAL) of active Behçet disease patients with pulmonary involvement. We report also correlations between BAL-BAFF levels and cell counts and that the levels of production were highly correlated with the appearance of the other B-cell-activating cytokines IL-6 and IL-13. 
Table 1. Clinical features of patients with Behçet disease (BD) with pulmonary involvement

\begin{tabular}{|cc|}
\hline Lesions & Number of patients (\%) \\
\hline Oral ulcer & $15(100 \%)$ \\
\hline Genital ulcer & $15(100 \%)$ \\
\hline Eye lesions & $10(66 \%)$ \\
Skin lesions & $8(53.3 \%)$ \\
\hline (erythema nodosum, folliculitis, ...) & $15(100 \%)$ \\
\hline Arthritis & $12(80 \%)$ \\
\hline Vascular symptoms &
\end{tabular}

Overall burden of the disease manifestations in BD patients is described. Patients received colchicine, steroids/cyclosporine. The pulmonary arteries are the second most common site of arterial involvement, preceded by the aorta. Aneurysms are more common than thrombosis. ${ }^{3}$

\section{Results}

Subject characteristics and inflammatory cells responses in BAL fluid. BAL fluids were collected from 15 subjects with BD and 18 healthy controls (Table 1). Recovery of BAL fluid did not differ between healthy controls(median, $42 \%$; range, $16 \%$ to $79 \%$ ) and active $\mathrm{BD}$ (median, $48 \%$; range, $19 \%$ to $82 \%$ ). As we expected, total BD-BAL cell numbers, lymphocytes, macrophages and neutrophils, were increased in significant numbers in active $\mathrm{BD}$ (Table 2).

Detection of BAFF in BAL fluid. Figure 1 depicts the ELISA results for BAFF. BAFF level were less than the limit of detection in 4/15 BAL from $\mathrm{BD}$ patients. In the 11 other patients BAFF protein levels were significantly increased (median, 53.8 $\mathrm{pg} / \mathrm{mL}$; range, $0-407.4 \mathrm{pg} / \mathrm{mL}$ ) compared to values obtained in healthy controls $(\mathrm{p}=0.001)$.

$\mathrm{BAFF}$ is known to circulate in the blood, and serum levels in active BD have been reported in the range of 190 to $440 \mathrm{pg} /$ $\mathrm{mL}{ }^{14}$ To elucidate whether an increase of BAFF protein levels in BAL fluid reflects local production in the airway or whether it reflects plasma leakage, we measured the concentration of albumin and used it as a marker of plasma exudation.

Albumin concentrations in BAL fluid were significantly increased in active $\mathrm{BD}(0.40 \mathrm{mg} / \mathrm{mL}$; range, $0.08-2.96 \mathrm{mg} / \mathrm{mL})$ compared to BAL from healthy controls $(0.030 \mathrm{mg} / \mathrm{mL}$; range, $0.010-2.030 \mathrm{mg} / \mathrm{mL}$ ). When we normalized the concentration of BAFF to the concentration of albumin in BAL fluid and serum, the BAFF concentration in BAL fluid of BD patients (314.49 $\pm 415 \mathrm{pg} / \mathrm{mg}$ albumin) was still significantly higher than in BAL fluid from healthy controls $(37.71 \pm 88.40 \mathrm{pg} / \mathrm{mg}$ albumin; $p=0.0096$; Fig. 1B). BAL-BAFF levels normalized to albumin still expressed at lower levels when compared with levels in sera $(6101.3+1831.82 \mathrm{pg} / \mathrm{mg}$ albumin; $\mathrm{p}=0.0001)$. These data suggested that BAFF is released in the airways.

Levels of BAFF correlate with inflammatory cells and cytokines. In the BD-BAL fluid, BAFF levels were strongly correlated with absolute numbers of total cells $(r=0.823, \mathrm{p}=$ 0.001) (Fig. 2A), lymphocytes $(r=0.709, \mathrm{p}=0.001)$ (Fig. 2C), macrophages $(r=0.742, \mathrm{p}=0.001)$ (Fig. 2B) and neutrophils $(r=0.809, \mathrm{p}=0.001)$ (Fig. 2D).

We also analyzed the concentrations of the other B-cellactivating cytokines IL- 6 and IL-13 in the BAL fluid and in the serum. Confirming previous reports, ${ }^{15-17}$ we observed that the concentrations of IL- 6 and IL-13 were significantly increased in serum from BD patients (Fig. 3A-C).

B-cell-activating cytokines in BAL fluid from active BD patients were expressed at higher levels than in BAL-fluid from healthy controls [IL-6: $99.0 \mathrm{pg} / \mathrm{ml}$ (17.80-125.0); IL-13: 109.0 $\mathrm{pg} / \mathrm{ml}(37.5-159.0)]$ when compared to healthy-BAL fluid [IL-6: $9.30 \mathrm{pg} / \mathrm{ml}(4.0-33.0) ;$ IL-13:3.0 pg/ml $(0.0-12.0)][p<0.0001]$ (Fig. 3A). Using BAL fluid data obtained from BD patients, we found that the levels of BAFF were strongly correlated with the levels of IL-6 $(r=0.882, \mathrm{p}<0.001)$ (Fig. 3B) and IL-13 $(r=$ 0.659, $\mathrm{p}<0.0001$ ) (Fig. 3C).

\section{Discussion}

BAFF is an important regulator of B-cell activation, proliferation and immunoglobulin production. ${ }^{8}$ This study provides the first demonstration that levels of BAFF, as well as the other B-cellactivating cytokines IL- 6 and IL-13, were significantly increased in BAL fluid of BD patients with pulmonary involvement. The concentrations of BAFF detected in BAL fluid were highly correlated with the absolute numbers of recruited inflammatory cells, including lymphocytes, macrophages and neutrophils. The concentrations of antigen-induced BAFF were also correlated with the concentrations of the other B-cell-active cytokines IL- 6 and IL-13. BAFF and BAFF mRNA were recently studied in BD, in the peripheral circulation, in skin lesion and in the central nervous system..$^{14,18}$

Pulmonary aneurysms represent the major complication of pulmonary Behçet disease and have a poor prognosis, being associated with massive haemoptysis. In situ pulmonary artery thrombus can lead to pulmonary infarction. Superior vena cava thrombosis progresses slowly, allowing the development of a prominent collateral circulation. Vascular inflammation can spread to the mediastinum, the pleura and the lungs with diffuse pulmonary haemorrhages, bronchiolitis and organising pneumonia. Electron beam tomodensitometry and MRI are the best diagnostic techniques for assessing pulmonary vascular lesions. ${ }^{3,4}$ Treatment of vasculitis in $\mathrm{BD}$ should be based on the type of vascular disease and may vary among different types of vascular disease.

In the current study we present the first evidence that BAFF levels are significantly increased in BAL fluid from BD patients. To eliminate the possibility that the result merely reflects vascular leakage, we normalized values to the concentration of albumin as an indicator of plasma leak. Normalized BAFF concentrations in BAL fluids were still significantly higher than those in BAL fluids of healthy controls. Serum BAFF levels were more increased in $\mathrm{BD}$ than in BAL fluid. Our results suggested that $\mathrm{BAFF}$ is produced locally in the lower airway of active $\mathrm{BD}$. These results do not totally eliminate the possibility that vascular leakage or active transport contribute to the increased appearance of 
Table 2. Inflammatory cells in bronchoalveolar lavage (BAL) fluid from Behçet disease (BD)

\begin{tabular}{|c|c|c|c|}
\hline & Control subjects & Behçet's disease & p value ${ }^{\alpha}$ \\
\hline Total cells $\left(10^{6}\right.$ cells) & $10.2(9.4-21.6)$ & $18.5(10.9-42.0)$ & 0.001 \\
\hline Macrophages ( $10^{6}$ cells) & $9.8(7.5-22.8)$ & $16.9(10.52-42.5)$ & 0.001 \\
\hline Lymphocytes (10 $10^{6}$ cells) & $0.8(0.4-5.8)$ & $4.7(1.9-22.8)$ & 0.001 \\
\hline Neutrophils $\left(10^{6}\right.$ cells) & $0.9(0.0-6.8)$ & $2.6(0.9-21.5)$ & 0.001 \\
\hline Eosinophils ( $10^{6}$ cells) & $0.1(0.0-1.2)$ & $0.1(0.0-1.5)$ & 0.92 \\
\hline
\end{tabular}

Values are presented as median (ranges). " Significance Behçet disease versus control subjects. BAL samples from 15 BD patients with pulmonary involvements and 18 healthy controls were investigated. Aliquots of fluid were removed for measurement of cell counts with a hemocytometer, cell viability was determined by means of trypan blue dye exclusion. Patients with BD exhibited increased values of total cell count in their BAL when compared to healthy controls. Significant differences were also observed Macrophages, lymphocytes and neutrophils were present in significant numbers in BAL from BD patients.

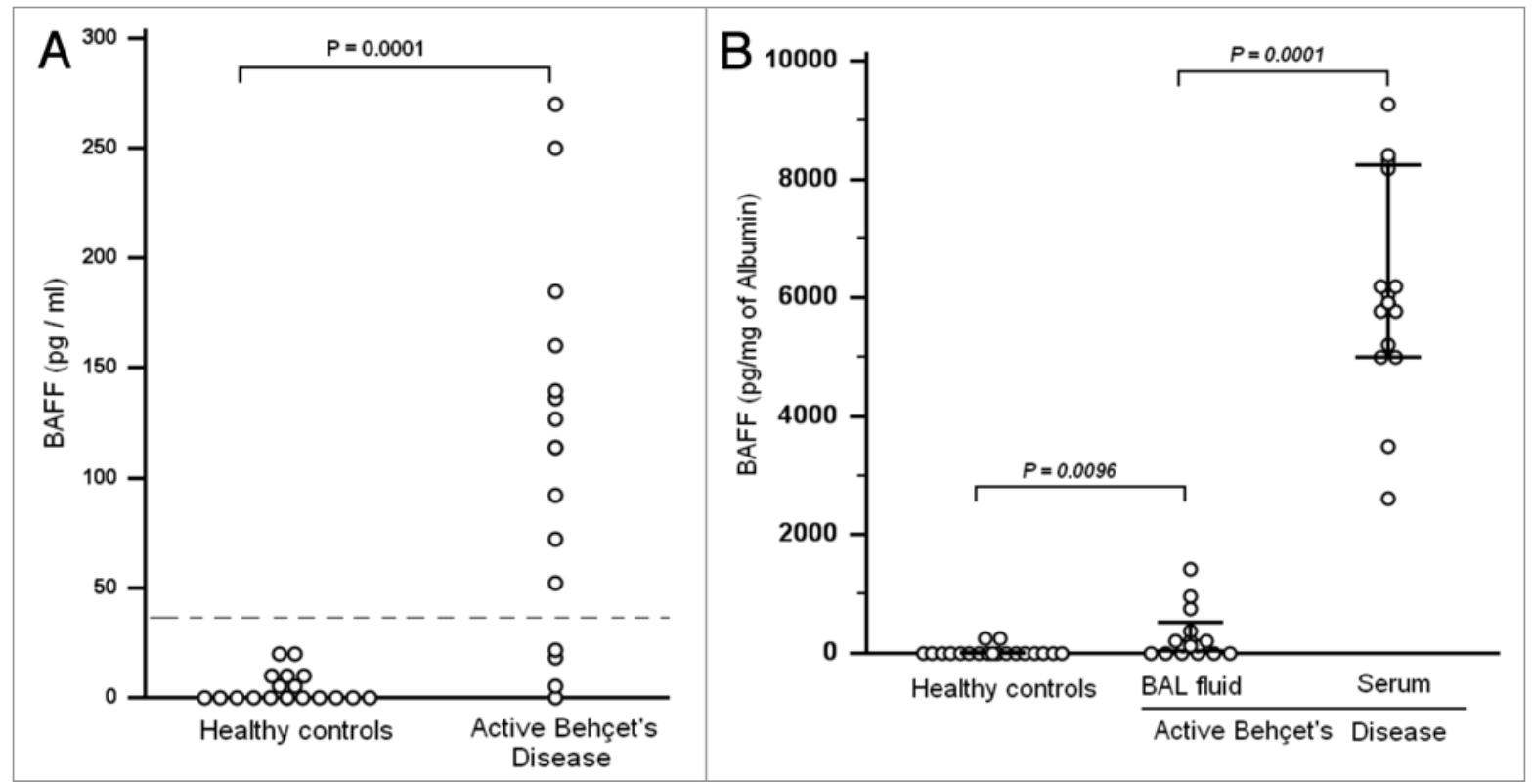

Figure 1. Increased B-cell-activating factor (BAFF) production in Bronchoalveolar lavage (BAL) fluid from active Behçet disease with pulmonary manifestations. Hatched line indicates the limit detection. (A) Measurement of BAFF in BAL fluids obtained was performed by using ELISA. The mean concentration of BAFF in active BD was increased $(109.53 \pm 21.78 \mathrm{pg} / \mathrm{mL})$ when compared with BAFF values in healthy controls $(4.83 \pm 1.72 \mathrm{pg} / \mathrm{mL})$. (B) BAFF concentration in BAL fluid was normalized to the concentration of albumin. BAFF concentration in BAL fluid of BD patients ( $314.49 \pm 415 \mathrm{pg} / \mathrm{mg}$ albumin) was still significantly higher than in healthy controls $(37.71 \pm 88.40 \mathrm{pg} / \mathrm{mg}$ albumin; $\mathrm{p}=0.0096)$; (B) suggesting that BAFF is produced locally in the lower airway of BD patients. These results do not totally eliminate the possibility that active transport contribute to the increased appearance of BAFF in BD-airways. Local production of BAFF might have either a protective or pathogenic role.

BAFF in antigen-challenged airways. IL-6 and IL-13 were also produced locally and their concentrations were strongly correlated with concentrations of BAFF. Collectively, these data suggest that local production of the B-cell-stimulating cytokines BAFF, IL-13 and IL-6 might play a role in local B-cell responses in the lower airways of patients with allergic inflammatory diseases.

Deregulated production of interleukin-6 (IL-6) has been found in several inflammatory/autoimmune disorders. ${ }^{19,20}$ Increased IL-6 levels have been reported in sera ${ }^{21-23}$ and in peripheral blood mononuclear cells of $\mathrm{BD}$ patients. ${ }^{24} \mathrm{In}$ a recent study, IL-6 level was found increased in another inflammatory site: the CNS. ${ }^{25}$ IL- 6 in CSF from BD predicted the long-term outcome of the patients. Some studies have found a correlation between serum IL-6 levels and disease activity. ${ }^{26,27}$
This study provides the first demonstration that IL-13-levels were significantly increased in BD-BAL fluid. Contradictory results were reported in serum-IL-13 level in BD. Increased IL-13 (Th2) level were reported in active $\mathrm{BD},{ }^{22}$ which contrasted with results from Raziuddin et al. ${ }^{23}$ We think that Th1/Th2 cytokines production is dependent of the inflammatory site. The presence of IL-13 in BAL from BD patient with pulmonary involvement could be partially explained by allergic inflammation considering the greater importance of IL-13 in the effector phase of allergic airway disease. The prevalence of Th2 cell-mediated diseases, such as atopic diseases, has been noted to be low in Th1-cellmediated diseases. Blood eosinophil count and serum total IgE levels were found low in $\mathrm{BD}$ patients compared to allergic bronchial asthma. ${ }^{24,28}$ However, high IgE levels were detected in certain patients with $\mathrm{BD}$ as in patients with bronchial hyperactivity. ${ }^{28}$ 


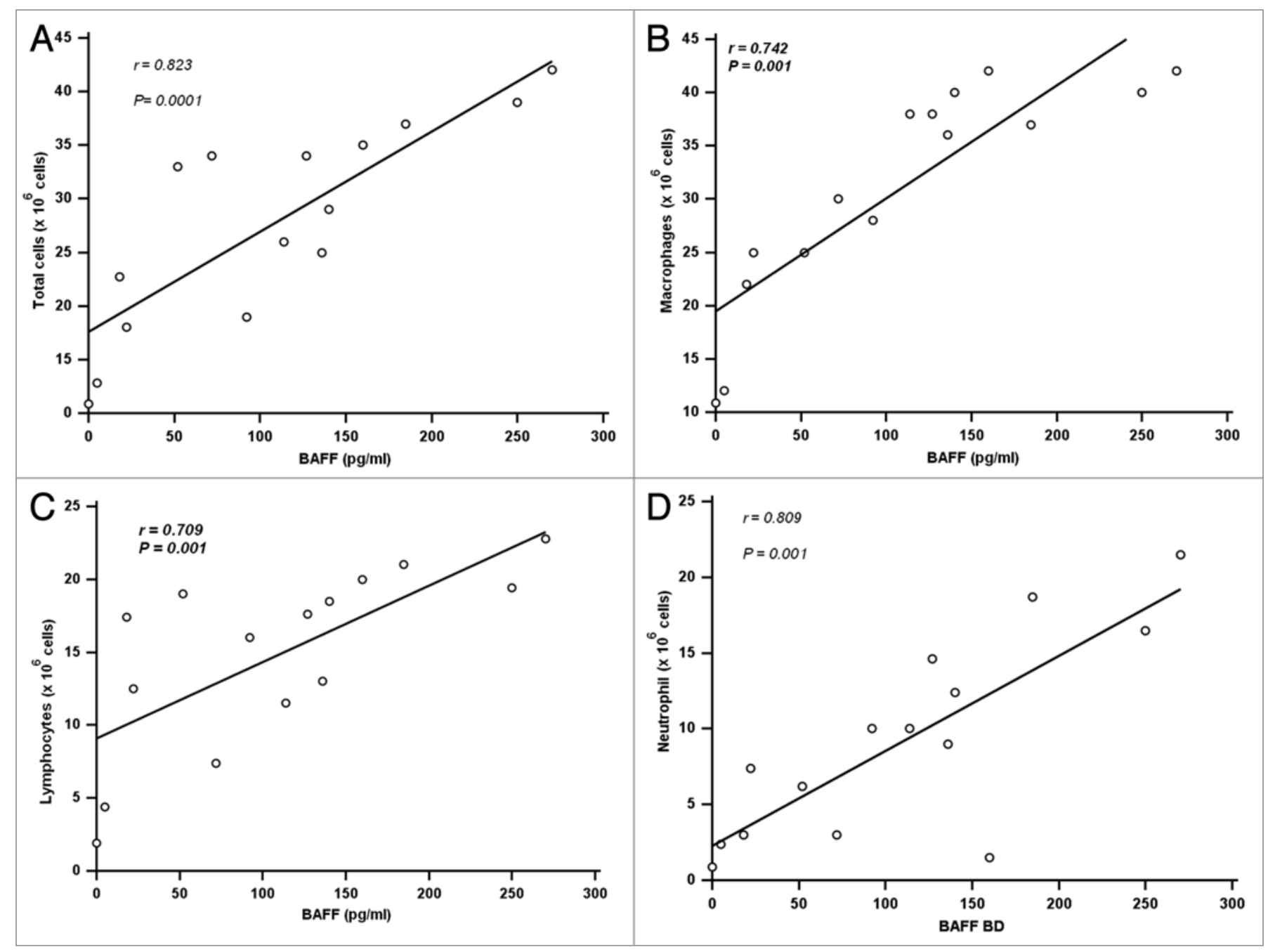

Figure 2. (A) Significant correlation of B-cell-activating factor (BAFF) with total ( $10^{6}$ cells) inflammatory cells. Cell viability was determined by means of trypan blue dye exclusion, and differential cell counts were obtained by using a Diff-Quik stain (American Scientific Products, McGaw Park, IL) of cytocentrifuge preparations (Cytospin; Shandon Southern Instruments, Inc., Sewickley, PA). Correlations were assessed with the Spearman rank correlation. Significant correlation was observed between BAFF level and bronchoalveolar lavage total inflammatory $\left(10^{6}\right)$ cells $(r=0.823, p=0.001)$. The concentrations of BAFF detected in BAL fluid were highly correlated with the absolute numbers of recruited inflammatory cells. (B) Significant correlation of B-cell-activating factor (BAFF) with bronchoalveolar lavage (BAL) macrophages $\left(10^{6}\right.$ cells). Differential cell counts were obtained by using Diff-Quik staining of cytocentrifuge preparations. Correlations were assessed with the Spearman rank correlation. Significant correlation was observed between BAFF level and BAL macrophages $(r=0.742, \mathrm{p}=0.001)$. The concentrations of BAFF detected in BAL fluid were highly correlated with the absolute numbers of macrophages. (C) Significant correlation of B-cell-activating factor (BAFF) with bronchoalveolar lavage (BAL) lymphocytes (10 ${ }^{6}$ cells) Differential cell counts were obtained by using Diff-Quik staining of cytocentrifuge preparations. Correlations were assessed with the Spearman rank correlation. Significant correlation was observed between BAFF level and BAL lymphocytes $(r=0.709, p=0.001)$. The concentrations of BAFF detected in BAL fluid were highly correlated with the absolute numbers of recruited inflammatory lymphocytes. (D) Significant correlation of B-cell-activating factor (BAFF) with bronchoalveolar lavage (BAL) neutrophils ( $10^{6}$ cells). Differential cell counts were obtained by using Diff-Quik staining of cytocentrifuge preparations. Correlations were assessed with the Spearman rank correlation. Significant correlation was observed between BAFF level and bronchoalveolar lavage fluid (BAL) neutrophils $(r=0.809, p=0.001)$. The concentrations of BAFF detected in BAL fluid were highly correlated with the absolute numbers of recruited neutrophils.

This result may probably reflect nonspecific inflammation which is seen in $\mathrm{BD} .{ }^{28}$

We did not identify the origins of BAFF production in the lower airways. It is well known that BAFF is produced by monocytes, macrophages, DCs, neutrophils and epithelial cells from several tissues, including lung. Several groups have reported that $\mathrm{T}$ and $\mathrm{B}$ lymphocytes are capable of producing BAFF. ${ }^{13,29,30}$ Our present study showed that BAFF concentrations in BAL fluid of
BD patients with pulmonary involvement were positively correlated with the numbers of macrophages, lymphocytes and neutrophils but not eosinophils. This suggests that infiltrating macrophages, lymphocytes and neutrophils might play a greater role in BAFF production in the airways.

Recently, it has been reported that BAFF levels are increased in nasal polyp tissue from patients with chronic rhinosinusitis and in the upper airway include mucosal epithelial cells and 
Figure 3. (A) Measurement of B-cell activators interleukin (IL)- 6 and IL-13 in bronchoalveolar lavage (BAL) from patients with Behçet disease (BD) with pulmonary manifestations. IL-6 and IL-13 levels were performed with cytometric bead array (CBA) assay as reported in materials and methods. Increased levels of IL- 6 and IL-13 were observed between BD patients and healthy controls $(p=0.0001)$. This result indicated an expanded production of inflammatory mediators in BAL from BD patients with pulmonary manifestation. Collectively, these data suggest that local production of the B cell-stimulating cytokines BAFF, IL-13 and IL- 6 might play a role in local B-cell responses, in the lower airways of patients with BD. (B) Correlations between B cell-activating factor (BAFF) (pg/ml) and interleukin (IL-6) levels in bronchoalveolar lavage (BAL) fluid. Correlation was assessed with the Spearman rank correlation. Significant correlation was obtained between BAFF and IL- 6 levels $(r=0.882 ; p<0.001)$ in Behçet disease (BD). (C) Correlations between B cell-activating factor (BAFF) ( $\mathrm{pg} / \mathrm{ml}$ ) and interleukin (IL-13) $(\mathrm{pg} / \mathrm{ml}$ ) levels in bronchoalveolar lavage (BAL) fluid. Correlation was assessed with the Spearman rank correlation. Significant correlation was obtained between BAFF and IL-13 levels $(r=0.659 ; p<0.001)$ in Behçet disease (BD).

unidentified infiltrating cells in the lamina propria ${ }^{28}$ and in BAL from asthmatics. ${ }^{31}$ This suggests that overproduction of BAFF contribute to the inflammation through expansion and activation of B-cells. This would support the suggestion that both infiltrating cells in BAL fluid and tissue epithelial cells might produce BAFF in the lower airways. In either case the correlation of local BAFF production with the influx of inflammatory cells suggests that BAFF production is an integral part of the inflammatory response. ${ }^{10,32}$ Future studies will be required to determine the precise nature of the BAFFproducing cells in the lung from $\mathrm{BD}$ patients with pulmonary involvement.

In summary, we report here that BAFF is upregulated in the BAL from BD patients with pulmonary involvement. BAFF levels were highly correlated with levels of IL-13 and IL-6. Our findings indicate that BAFF and other B-cell-stimulating cytokines are produced locally in the BAL and might contribute to local B-lymphocyte responses in airway inflammatory $\mathrm{BD}$ and in host defense. These results suggest that BAFF and its signaling in B-cells contribute to B-cell abnormalities and the development of pulmonary manifestation in patients with BD. Production of BAFF in inflammatory sites might have either a protective or pathogenic role in immunity.

\section{Methods}

Patients. We studied 15 active BD patients (14 males and 1 female; nonsmoking patients; mean age: 47.5 years; range: 32-56 years). They were selected on the basis of the criteria defined by the International Study Group for diagnosis of Behçet disease. ${ }^{1}$ Clinical features of the patients with active stage are given in Table 1, which describe overall burden of the disease manifestations in $\mathrm{BD}$ patients. All active $\mathrm{BD}$ patients have pulmonary manifestations. Active BD patients were always treated with steroids and colchicine. The control subjects consisted of 18 nonsmokers ( 16 men and 2 women; mean age: 45.4 years; range: $37-45$ years) undergoing routine investigations for suspected bronchial carcinoma and

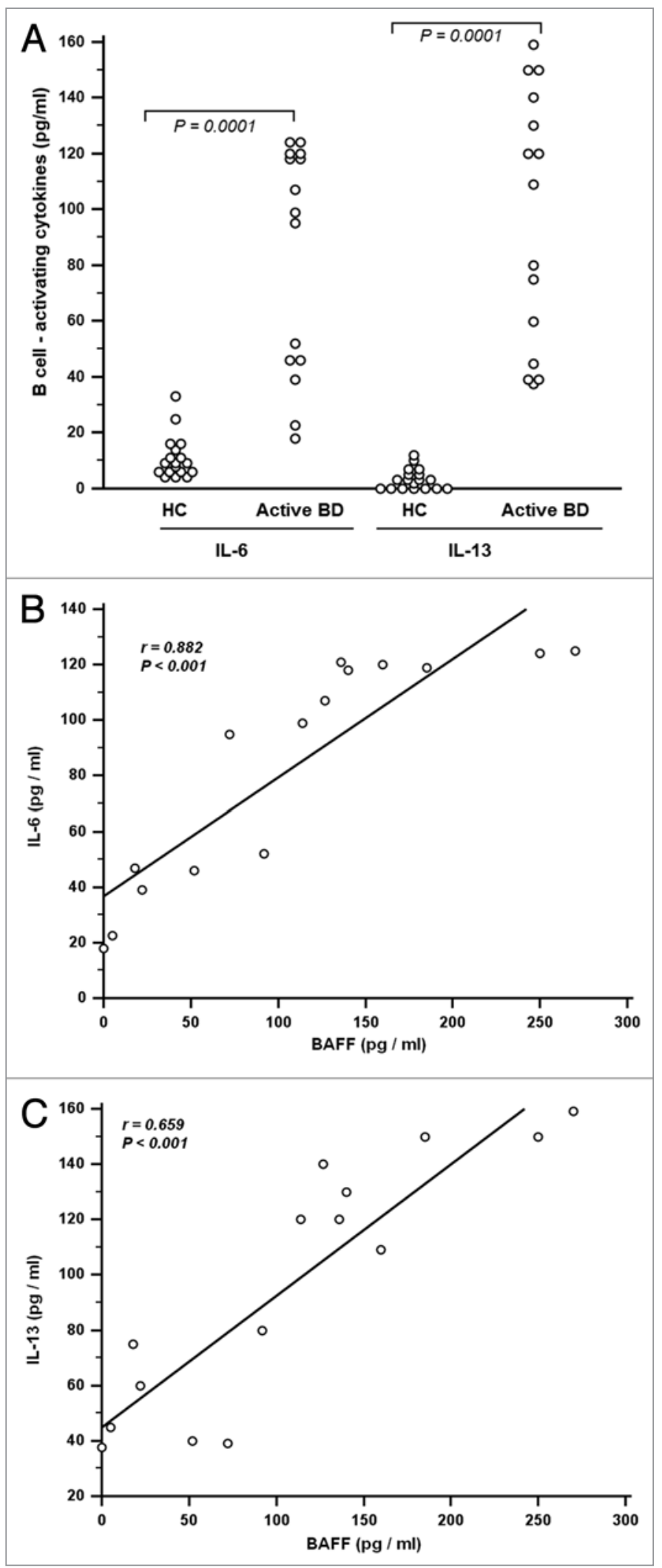

whose chest X-ray (CXR), bronchial examination, and pulmonary functions were normal. None of them had evidence of acute infection or chronic disease (e.g., other autoimmune or atopic disorders). Informed consent was obtained from all of 
the patients and control subjects. The design of the study was approved by our National Ethics Committee.

Bronchoalveolar lavage. Bronchoscopy was performed according to standard guidelines, as described previously. ${ }^{33}$ Thirty minutes prior to the procedure patients received $0.5 \mathrm{mg}$ of atropine and $12.5 \mathrm{mg}$ codeine intramuscularly. Local anaesthesia of the oropharynx was achieved by Novesine spray (Wander, Switzerland) until gag reflexes subsided. Bronchoscopy was performed using a Pentax bronchoscope through which $150 \mathrm{ml}$ of normal prewarmed saline in aliquots of $20 \mathrm{ml}$ were instilled into a subsegment of the right middle lobe. BAL fluid was then immediately aspirated by gentle hand suction into plastic tubes and kept at $4^{\circ} \mathrm{C}$ on ice.

Processing of BAL cells. BAL samples were filtered through a two-layer sterile gauze into sterile plastic vials (Falcon, Oxnard, $\mathrm{CA}$ ), centrifuged at $4^{\circ} \mathrm{C}$ and $500 \mathrm{~g}$ for 10 minutes. The supernatant was removed and cells were washed twice in PBS. The total cell number was counted using a Neubauer hemocytometer (Brand, Wertheim, Germany). Differential cell counts were performed after Giemsa staining (Merck, Darmstadt).

Cell counts. The volume of fluid recovered from each $100-\mathrm{mL}$ lavage specimen was recorded. Before centrifugation, aliquots of fluid were removed for measurement of cell counts with a hemocytometer, cell viability was determined by means of trypan blue dye exclusion, and differential cell counts were obtained by using a Diff-Quik stain (American Scientific Products, McGaw Park, IL) of cytocentrifuge preparations (Cytospin; Shandon Southern Instruments, Inc., Sewickley, PA), as previously described. ${ }^{33}$ Total cells were calculated as the volume of BAL fluid recovered multiplied by cells per milliliter by hemocytometer count. Total counts of each cell type were calculated as total cells multiplied by the percentage of each cell type determined by differential cell counts.

Soluble protein measurement. The concentrations of BAFF (R\&D Systems, Minneapolis, MN), albumin (Bethyl
Laboratory, Montgomery, TX), IgA (Bethyl Laboratory), and sIgA (ALPCO Diagnostics, Salem, NH) in BAL fluids were measured with specific ELISA kits as we have recently reported. ${ }^{18,33}$ The minimal detection limits for BAFF is $31 \mathrm{pg} / \mathrm{mL}$.

The concentrations of albumin (Bethyl Laboratory, Montgomery, Tex), IgA (Bethyl Laboratory), and sIgA (ALPCO Diagnostics, Salem, NH) in BAL fluids were measured with specific ELISA kits. The minimal detection limits for these kits are $6.25 \mathrm{ng} / \mathrm{mL}, 7.8 \mathrm{ng} / \mathrm{mL}$ and $22.2 \mathrm{ng} / \mathrm{mL}$, respectively. The concentrations of IL-6, IL-17 and MMP-9 in BAL fluids were measured by using a cytometric bead array (CBA) human IL-6 Flex Set. In brief, $50 \mu \mathrm{L}$ of the mixed capture beads and $50 \mu \mathrm{L}$ of BAL fluid were incubated for 1 hour at room temperature. After adding $50 \mu \mathrm{L}$ of the phycoerythrin detection reagent to the mixture and incubation for 2 hours at room temperature, the beads were then washed with the wash buffer and analyzed with a BD FACSArray Bioanalyzer (BD Biosciences). The CBA data were analyzed with FCAP Array software version 1.0.1 (BD Biosciences). The minimal detection limits are $5 \mathrm{pg} / \mathrm{mL}(\mathrm{IL}-6)$, $5 \mathrm{pg} / \mathrm{mL}(\mathrm{IL}-13)$ and $1 \mathrm{ng} / \mathrm{mL}(\mathrm{IgE})$.

Statistical analysis. All data are reported as medians (ranges, minimum to maximum). Differences between groups were analyzed by using the Wilcoxon signed-rank test or the MannWhitney $U$ test. Correlations were assessed by using Spearman rank correlation. A p value of less than 0.05 was considered significant.

\section{Acknowledgements}

Our unit research (Homeostasis and Cell Dysfuction: 99/UR/ O8-40) had the financial support of "High Education Ministery of Science and Research of Tunisia." The authors wish to thank Neziha Ben Hamida (Anatomopathology department, Isntitute of Cancerology) for her technical assistance.

This study was supported by grant from the: "Ministère de l'Enseignement Supérieur de la Recherche Scientifique et de la Technologie" of Tunisia (DGRST Staff).

\section{References}

1. International Study Group for Behçet's Disease. Criteria for diagnosis of Behçet's disease. Lancet 1990; 335:1078-80.

2. Yazici H, Esen F. Mortality in Behçet's syndrome. Clin Exp Rheumatol 2008; 26:138-40.

3. Uzun O, Erkan L, Akpolat I, et al. Pulmonary involvement in Behçet's disease. Respiration 2008; 75:31021.

4. Hamzaoui A, Hamzaoui K. Pulmonary complications of Behcet's disease and Takayasu's arteritis. Rev Mal Respir 2005; 22:999-1019.

5. Tavil B, Kuskonmaz B, Kiper N, et al. Pulmonary thromboembolism in childhood: a single-center experience from Turkey. Heart Lung 2009; 38:56-65.

6. Uchiyama M, Nagao T, Hattori A, et al. Pulmonary alveolar proteinosis in a patient with Behcet's disease. Respirology 2009; 14:305-8.

7. Moisini I, Davidson A. BAFF: a local and systemic target in autoimmune diseases. Clin Exp Immunol 2009; 158:155-63.

8. Khan WN. B cell receptor and BAFF receptor signaling regulation of B cell homeostasis. J Immunol 2009; 183:3561-7.
9. Gould HJ, Takhar P, Harries HE, et al. Germinal-centre reactions in allergic inflammation, Trends Immuno 2006; 27:446-52.

10. Kim YH, Choi BH, Cheon HG, et al. B cell activation factor (BAFF) is a novel adipokine that links obesity and inflammation. Exp Mol Med 2009; 41:208-16.

11. Mackay F, Schneider P. Cracking the BAFF code. Nat Rev Immunol 2009; 9:491-502.

12. Krystufková O, Vallerskog T, Helmers SB, et al. Increased serum levels of $\mathrm{B}$ cell activating factor (BAFF) in subsets of patients with idiopathic inflammatory myopathies. Ann Rheum Dis 2009; 68:836-43.

13. Kato A, Peters A, Suh L, et al. Evidence of a role for B cell-activating factor of the TNF family in the pathogenesis of chronic rhinosinusitis with nasal polyps. J Allergy Clin Immunol 2008; 121:1385-92.

14. Hamzaoui K, Houman $\mathrm{H}$, Ben Dhifallah I, et al. Serum BAFF levels and skin mRNA expression in patients with Behçet's disease. Clin Exp Rheumatol 2008; 26:64-71.

15. Aridogan BC, Yildirim M, Baysal V, et al. Serum Levels of IL-4, IL-10, IL-12, IL-13 and IFNgamma in Behçet's disease. J Dermatol 2003; 30:602-7.

16. Akman-Demir G, Tüzün E, Içöz $S$, et al. Interleukin-6 in neuro-Behçet's disease: association with disease subsets and long-term outcome. Cytokine 2008; 44:373-
17. Adam BE. Calikoglu, Serum interleukin-6, procalcitonin and C-reactive protein levels in subjects with active Behçet's disease. J Eur Acad Dermatol Venereol 2004; 18:318-20.

18. Hamzaoui $\mathrm{K}$, Hentati F, Hamzaoui A. BAFF is upregulated in central nervous system of neuro-Behçet's disease. J Neuroimmunol 2008; 200:111-4.

19. Bettini M, Vignali DA. Regulatory T cells and inhibitory cytokines in autoimmunity. Curr Opin Immunol 2009; 21:612-8.

20. Cash H, Relle M, Menke J, et al. Interleukin 6 (IL-6) deficiency delays lupus nephritis in MRL-Faslpr mice: the IL-6 pathway as a new therapeutic target in treatment of autoimmune kidney disease in systemic lupus erythematosus. J Rheumatol 2010; 37:60-70.

21. Adam B, Calikoglu E. Serum interleukin-6, procalcitonin and C-reactive protein levels in subjects with active Behçet's disease. J Eur Acad Dermatol Venereo 2004; 18:318-20.

22. Mege L, Dilsen N, Sanguedolce V, et al. Overproduction of monocyte derived tumor necrosis factor alpha, interleukin (IL) 6, IL-8 and increased neutrophil superoxide generation in Behçet's disease. A comparative study with familial Mediterranean fever and healthy subjects. J Rheumatol 1993; 20:1544-9.

23. Raziuddin S, al-Dalaan A, Bahabri S, et al. Divergent cytokine production profile in Behçet's disease. Altered Th1/Th2 cell cytokine pattern. J Rheumatol 1998; 25:329-33. 
24. Dinç A, Karaayvaz M, Caliskaner AZ, et al. Dermographism and atopy in patients with Behçet's disease. J Investig Allergol Clin Immunol 2000; 10:368-71.

25. Akman-Demir G, Tüzün E, Içöz S, et al. Interleukin-6 in neuro-Behçet's disease: association with disease subsets and long-term outcome. Cytokine 2008; 44:3736.

26. Hamzaoui K, Hamzaoui A, Guemira F, et al. Cytokine profile in Behçet's disease patients. Relationship with disease activity. Scand J Rheumatol 2002; 31:205-10.

27. Evereklioglu C, Er H, Türköz Y, et al. Serum levels of TNFalpha, sIL-2R, IL-6 and IL- 8 are increased and associated with elevated lipid peroxidation in patients with Behçet's disease. Mediators Inflamm 2002; 11:8793.
28. Kalpaklioglu AF, Gürbüz L, Gürler A, et al. Bronchial hyperreactivity and immunoglobulin $\mathrm{E}$ in Behçet's disease. Allergol Immunopathol 1997; 25:182-8.

29. Huard B, Arlettaz L, Ambrose C, et al. BAFF production by antigen-presenting cells provides $\mathrm{T}$ cell costimulation. Int Immunol 2004; 16:467-75.

30. Darce JR, Arendt BK, Chang SK, et al. Divergent effects of BAFF on human memory B cell differentiation into Ig-secreting cells. J Immunol 2007; 178:5612-22.

31. Kato A, Xiao H, Chustz RT, et al. Local release of B cell-activating factor of the TNF family after segmental allergen challenge of allergic subjects. J Allergy Clin Immunol 2009; 123:369-75.
32. Walters $S$, Webster KE, Sutherland A, et al. Increased $\mathrm{CD}^{+}{ }^{+} \mathrm{Foxp} 3^{+} \mathrm{T}$ cells in BAFF-transgenic mice suppress $\mathrm{T}$ cell effector responses. J Immunol 2009; 182:793801

33. Hamzaoui A, Ghraïri H, Ammar J, et al. IL-18 mRNA expression and IFN $\gamma$ induction in bronchoalveolar lavage from Behçet's disease. Clin Expe Rheumato 2003; 21:8-14. 


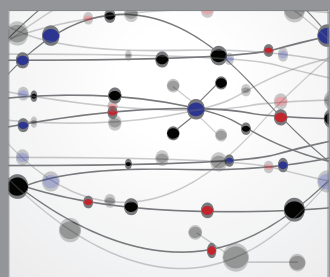

The Scientific World Journal
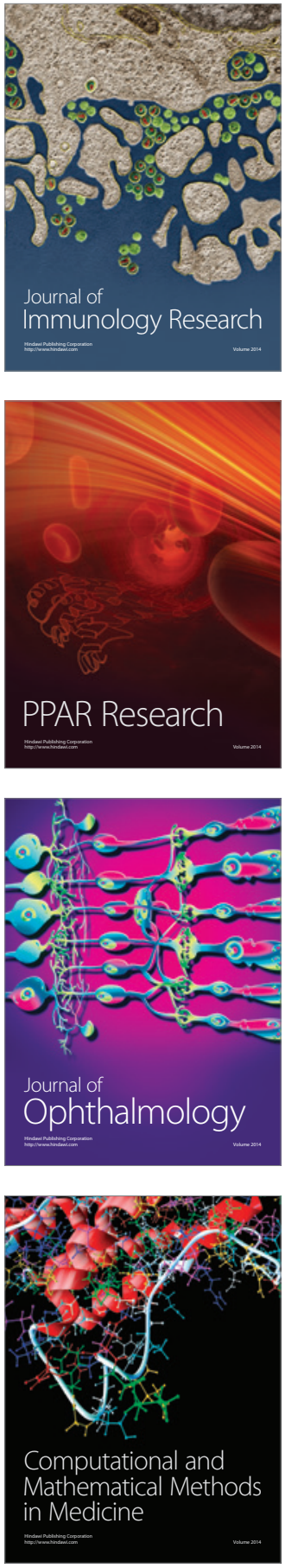

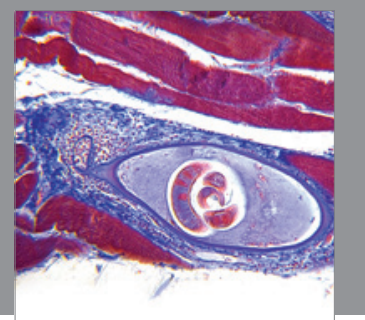

Gastroenterology

Research and Practice
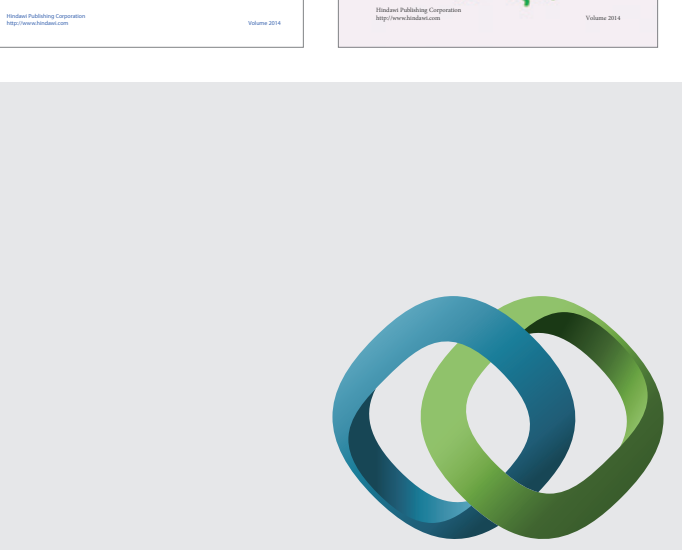

\section{Hindawi}

Submit your manuscripts at

http://www.hindawi.com
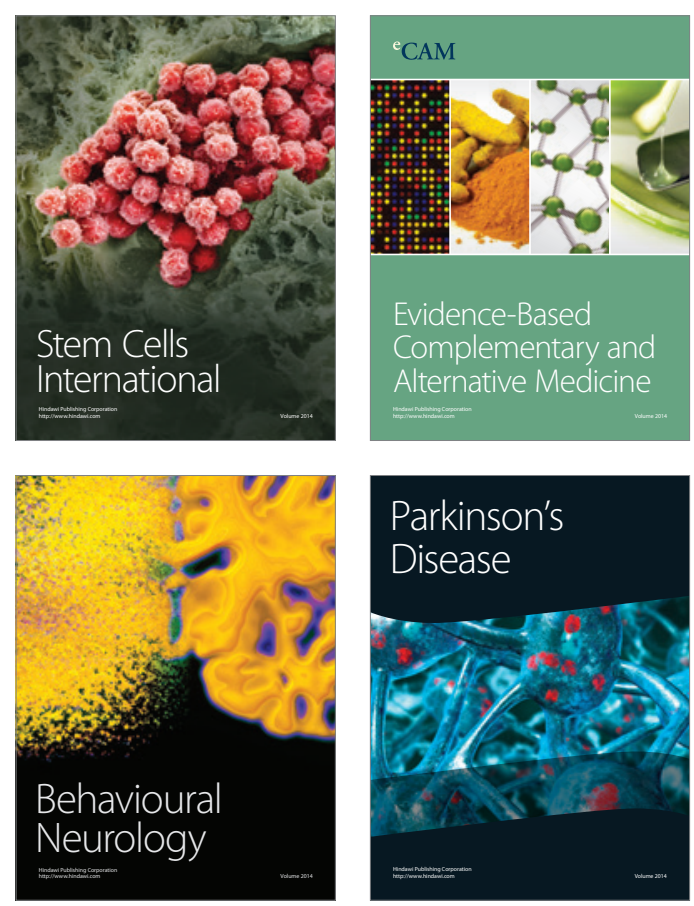

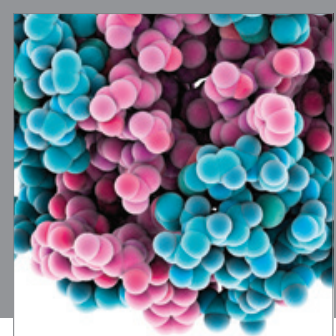

Journal of
Diabetes Research

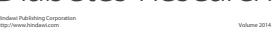

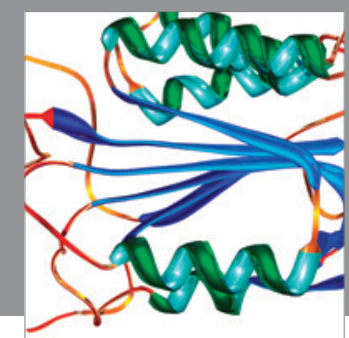

Disease Markers
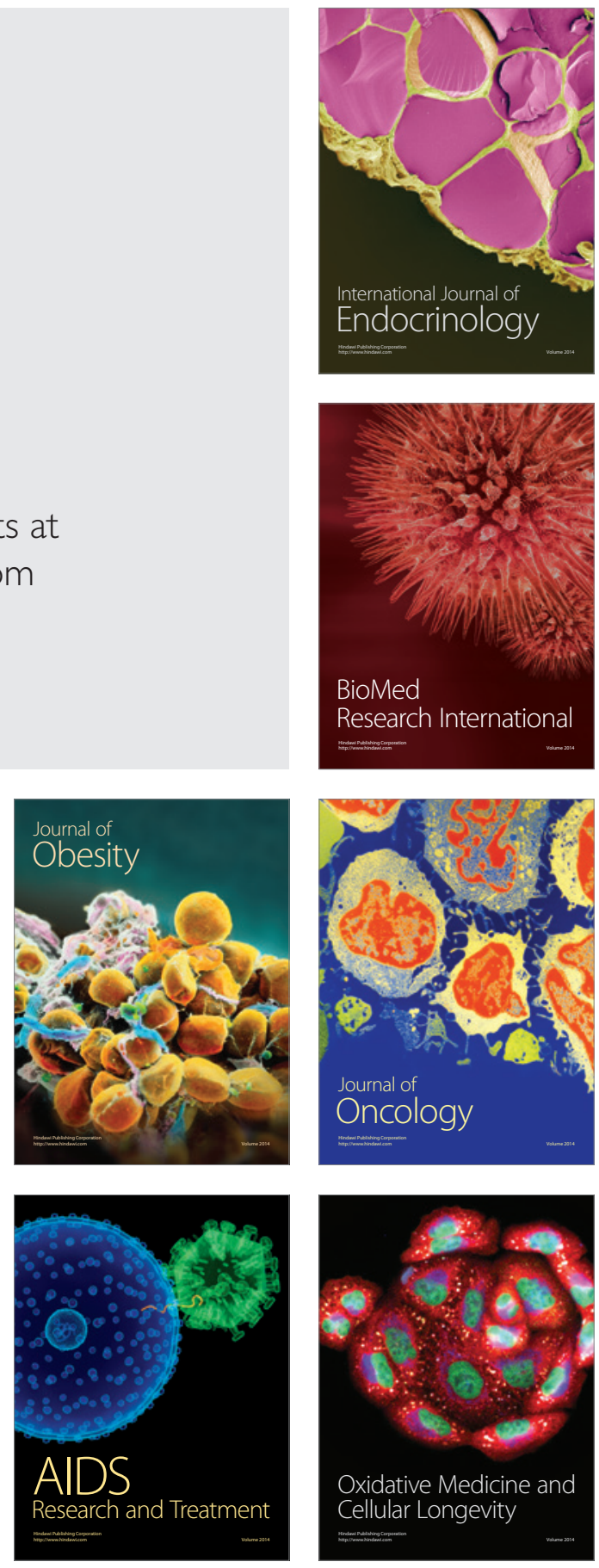